\title{
Disruption of Tight Junction Integrity, and Induced Mammary Involution in Lactating Goats by Saponins
}

\author{
S.J. Mabjeesh ${ }^{*}, 1$, Z. Kerem ${ }^{2}$, C. Sabastian ${ }^{1}$ and A. Shamay ${ }^{3}$ \\ ${ }^{I}$ Department of Animal Science and ${ }^{2}$ Institute of Biochemistry, Food Science and Nutrition, Faculty of Agricultural, \\ Food and Environmental Quality Sciences, the Hebrew University of Jerusalem, P.O. Box 12, Rehovot 76100, Israel \\ ${ }^{3}$ Agricultural Research Organization (ARO), the Volcani Center, Institute of Animal Science. P.O. Box 6, Bet Dagan, \\ 50250, Israel
}

\begin{abstract}
Four multiparous pregnant Nubian goats at late lactation were subjected to injection of a saponin preparation from Gypsophila roots. Saponin solution was injected into one single gland of each goat after milking 8 times. At day 2 in treatment, milk yield began to be affected, and dropped down dramatically from day 3 till dry off at day 8 . The $\mathrm{pH}$ value of milk was increased in udder halves treated with the saponin solution after 2 days, whereas the control halves exhibited semi-plateau manner all over the experiment. Sodium concentration increased and potassium concentration decreased after $2 \mathrm{~d}$ in treatment. Calcium concentration in the treated udder declined after $8 \mathrm{~d}$ and the values of these ions were roundabout the plasma concentrations indicating that milk secreted from the treated udder halves with saponins was mostly composed of interstitial fluid.
\end{abstract}

Keywords: Mammary gland, saponins, dry up, Gypsophila.

\section{INTRODUCTION}

Mammary gland involution proceeds through several distinct stages that involve cessation of milking, apoptosis of epithelial cells and tissue remodeling. Unilateral cessation of milking in goat's [1], and teat sealing in mice $[2,3]$ induced involution in the treated gland only. This specificity suggests that mammary involution is triggered by local stimuli, but the precise mechanism has not been defined $[4,5]$. Reinitiating milk removal can reverse the first stage of involution, but the second stage of involution is irreversible and is characterized by activation of protease that destroys the lobularalveolar structure of the gland by degrading the extracellular matrix and basement membrane, and causes massive loss of alveolar cells $[4,5]$. The two stages exhibit characteristic changes in gene expression or activity in the tissue.

During lactation, when the ducts and alveoli are filled with milk, the secretory epithelium is positioned between two very different environments: the milk, containing high concentration of lactose and low concentrations of sodium and chloride, and interstitial fluid containing low concentration of lactose and high concentrations of sodium and chloride. Thus, when tight junctions (TJ) are disrupted the $\mathrm{Na}^{+}$ concentration in the milk rises, whereas that of $\mathrm{K}^{+}$declines [6]. Tight junction in the epithelial cells of the mammary gland forms a barrier between the systemic (basolateral) and the milk (apical sides) and prevents paracellular transport [7]. Milk stasis causes the accumulation of local signals, which makes the TJ leaky [7]. The serine protease plasmin is the predominant protease in milk and is known to produce boiling-resistant-peptides (proteose-peptones) from $\beta$-casein

*Address correspondence to this author at the Department of Animal Science Faculty of Agricultural, Food and Environmental Quality Sciences, the Hebrew University of Jerusalem, P.O. Box 12, Rehovot 76100, Israel; Fax:+972-8-948979; E-mail: mabjeesh@agri.huji.ac.il
(CN) and $\alpha$ s1- and $\alpha$ s2-CN [8]. Maintenance of extracellular $\mathrm{Ca}^{2+}$ levels is essential for maintaining the TJ integrity of the mammary secretory epithelium $[9,10]$. Neville and Peaker [9] and Stelwagen et al. [11] found that introducing the Cachelator EGTA into the mammary gland induced transient loss of TJ integrity and transient reduction of milk yield. Recently it was shown that casein hydrolysate peptides disrupted epithelial cell $\mathrm{TJ}$ integrity and block $\mathrm{K}$ channels, and induced dry-up of milk secretion in goats and cows $[12,13]$. It was reported that those peptides lowered the $\mathrm{Ca}^{2+}$ concentration in mammary secretion, and induced irreversible involution by preventing the restoration of $\mathrm{TJ}$ integrity for a critical period.

Hence, natural occurring substances that may affect these orchestrated channels, TJs and other physiological events at the level of the mammary gland might cause and initiate apoptosis in the gland. Saponins, that are naturally occurring surface-active glycosides, were shown to block membrane ion channels on neurons [14] and human neutrophils [15]. In other works, saponins enhanced sarcolemmal membrane $\mathrm{Ca}^{2+}$ permeability [16]. Fluctuating membrane channels were suggested to explain the increase in electrical conductance caused by saponins in planar lipid bi-layers [17]. Soyasaponins I and III, and dehydrosoyasaponin I (isolated from Desmodium adscendens) were shown to be able to open large Ca-dependent K (maxi-K) conductance channels causing membrane hyperpolarization, suppression of electrical activity and relaxation of smooth muscle [18].

A large number of the biological effects of saponins have been ascribed to their action on membranes. In fact, their specific ability to form pores in membranes has contributed to their common use in physiological research $[19,20]$. Saponins have long been known to have a lytic action on erythrocyte membranes and this property is commonly used for their detection. The haemolytic action of saponins is believed to be the result of the affinity of the aglycone moiety 
for membrane sterols, particularly cholesterol [3], with which they form insoluble complexes [3]. The lesions that are caused by saponins are thought to be a micelle-like aggregation of saponins and cholesterol in the plane of the membrane, possibly with saponin molecules arranged in a ring with their hydrophobic moieties combined with cholesterol around the outer perimeter [21, 22]. Saponins such as ophiopogonins and ginsenosides haemagglutinated human, rabbit, and sheep erythrocytes but were not haemolytic [23]. They were thus able to bind to the membrane lipids of erythrocytes and form bridges between the cells. Conversely, the commercial Merck saponin (E. Merck No. 7695), also known as Saponin Pure White, is a crude saponin fraction obtained from roots and rhizomes of Gypsophyla paniculata. Due to its high haemolytic properties, it has been extensively used in the past as a standard for haemolytic tests in most saponin determinations, and its composition has been determined [7].

Hence, in this study we hypothesize that saponins extracted from the roots and rhizomes of Gypsophila paniculata will cause a significant change in the apical membrane of the epithelial cells of ruminant's udder and dry up milk secretion.

\section{MATERIALS AND METHODS}

\section{Animals}

Multiparous pregnant $(110 \pm 14$ days in gestation; $\mathrm{BW}=$ $64 \pm 7 \mathrm{~kg})$ Nubian goats $(\mathrm{n}=4)$ at late lactation $(150 \pm 20$ days in milk) that were scheduled for dry-off treatment were used in the experiment. All goats were subjected to the normal milking and husbandry regimes in the metabolic goat house in the Faculty of Agriculture. Goats were milked twice daily at 7:00 and 16:00 and milk was recorded daily for each udder half. Goats were fed concentrated pellets and vetchclover hay at 3:2 ratio. The basic milk and milk composition were recorded for each udder half for 3 days before the onset of the experiment.

\section{Saponin Solution}

The commercial Merck saponin (E. Merck No. 7695), which is a crude saponin fraction obtained from roots and rhizomes of Gypsophila paniculata, was dissolved in isotonic water solution $(50 \mathrm{mg} / \mathrm{ml})$. Before injection into the teat the solution was sterilized by passage through $22-\mu \mathrm{m}$ sterile filter and kept in sealed glass $(2 \mathrm{ml})$ containers at $4^{\circ} \mathrm{C}$ till its use. The concentrations of saponin were chosen based on a preliminary experiment (data not shown) that give wanted effects. The control solution contained only the isotonic solution and was treated as described above.

\section{Experimental Procedure}

All goats during the experimental period were hand milked and stripped to ensure complete milk removal. A single dose of the saponin solution ( $50 \mathrm{mg} / \mathrm{d}$ per udder half) was injected with a thin, rounded stainless-steel needle, through the teat canal, into the cistern of one single gland (udder half) of each goat after the morning milking. The contralateral half was treated with the same volume of the control saline solution. This procedure was repeated after the afternoon milking and similarly on the next $4 \mathrm{~d}$ (i.e., eight postmilking doses over $4 \mathrm{~d}$ ). After the last treatment, the goats were not milked throughout the dry period ( $\sim 45 \mathrm{~d})$, and milking was resumed in the next lactation cycle. Mammary secretions $(\sim 50 \mathrm{ml})$ from each gland were collected and sampled at each dosing. Temperature and $\mathrm{pH}$ were measured in fresh samples immediately after milking. In addition, a sample was taken from each gland daily at each milking occasion, $3 \mathrm{~d}$ before the treatment, and during the experiment till dry up and subjected to mineral analysis. All milk samples were kept at $-20^{\circ} \mathrm{C}$ till analysis.

\section{Analytical Methods}

Mammary secretions were prepared for minerals ( $\mathrm{Na}, \mathrm{K}$, and $\mathrm{Ca}$ ) analysis and were measured with an inductively coupled plasma-atomic emission spectrometer (Spectro, Germany). Whole milk was prepared by digestion of the sample with $65 \% \mathrm{HNO}_{3}$ in teflon vessels by microwave digestion system (MLS 1200 maega, Italy).

\section{Statistical Analysis}

The data sets of this study were analyzed using repeated measures analysis by ANOVA procedure [24]. The model included the effect of treatment, day, and treatment $x$ day. Interaction effect was not significant though the effects in the model were reduced accordingly.

\section{RESULTS AND DISCUSSION}

Milk yield of goats is presented in Fig (1). Milk yield was affected as soon as day 1 in treatment, and consequently dropped down dramatically $(P<0.05)$ from day 3 till dry off at day 8 . Differences in milk $\mathrm{pH}$ values between treatment groups were significant. $\mathrm{pH}$ value of the milk was increased when udder halves were treated with the saponins solution, whereas the control halves exhibited semi-plateau manner all over the experiment. Values were significant beginning from day 1 in treatment (Fig. 2).

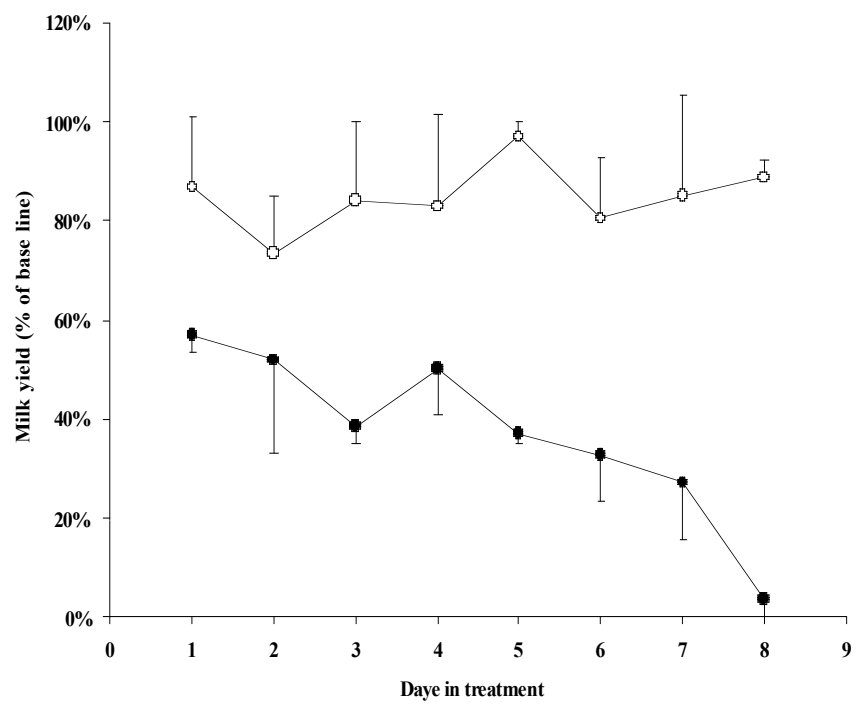

Fig. (1). Milk yield of udder halves of goats subjected to intramammary injection of Saponins; Merck saponin (E. Merck No. 7695; full circles) or control solutions (open circles). Means are different from day 3 in treatment $P<0.05$.

Fig. (3) describes the effect of treatment on concentrations of $\mathrm{Ca}^{2+}, \mathrm{K}^{+}$and $\mathrm{Na}^{+}$in milk secreted from the udder 
halves of goats. A dramatic changes $(P<0.05)$ in $\mathrm{Na}^{+}$(four fold increase), $\mathrm{K}^{+}$(decrease of $82 \%$ ) and $\mathrm{Ca}^{2+}$ (decline of $40 \%$ ) concentrations were recorded at the last day of the experiment. However, these changes were observed at day one for $\mathrm{Na}^{+}$and $\mathrm{K}^{+}$and at day 9 for $\mathrm{Ca}^{2+}$. These values were roundabout the plasma concentrations indicating that milk secreted from the treated udder halves with saponins was mostly composed of interstitial fluid.

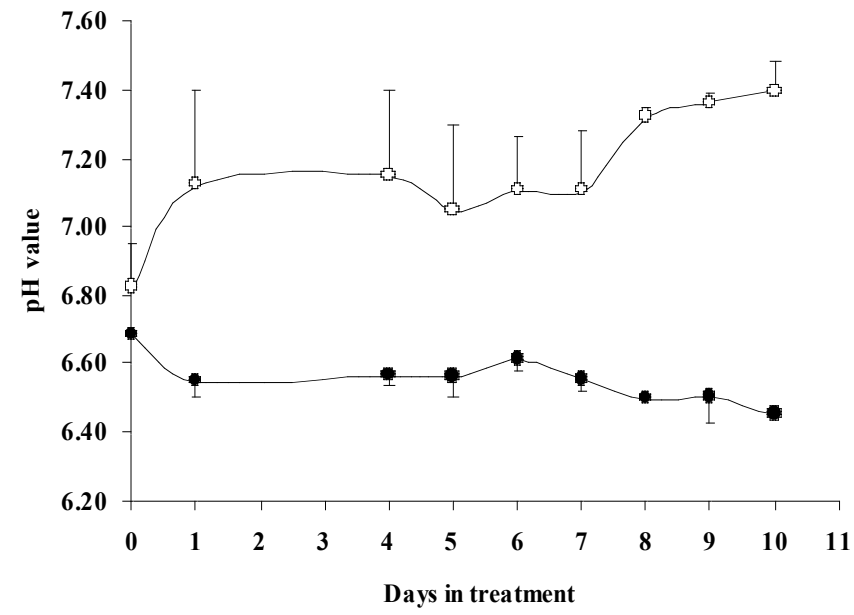

Fig. (2). $\mathrm{pH}$ value in milk of udder halves of goats subjected to intra-mammary injection of Saponins; Merck saponin (E. Merck No. 7695; full circles) or control solutions (open circles). Means are different from day 1 in treatment $P<0.05$.

The changes in $\mathrm{Na}^{+}$and $\mathrm{K}^{+}$concentrations in milk may indicate that the TJs in the treated glands were either compromised or cells became leaky. The mechanism by which disruption of TJ affects milk secretion has not been established [6]. A change in the $\mathrm{Na}^{+} / \mathrm{K}^{+}$ratio in milk could alter the intracellular $\mathrm{Na}^{+} / \mathrm{K}^{+}$ratio in the mammary epithelial cells and thus affect their functioning [6].

Considering the different routes that saponins might act on membrane structure and integrity (including channels and other functional proteins) the observed results suggest that the treated udder halves underwent involution process which might be initiated by disruption of interepithelial adhesion before the onset of complete apoptosis [25]. Furthermore, the equilibrium of ions concentration in milk and plasma, indicated that paracellular leakage of interstitial fluid into the milk occurred during the treatment [26].

The current experiment was not designed to study the mechanisms in which the saponins from Gypsophila paniculata act on the mammary cells. However, the dramatic changes in ionized $\mathrm{Na}, \mathrm{K}$, and $\mathrm{Ca}$ in milk followed by dry off might indicate that saponins induced membrane damage, and consequently drove the signals for involution. The disruptions of blood vessels and of alveolus integrity are typical events in either inflammation or involution and account for the influx of lymphocytes and phagocytes into the alveolar lumen. Thus, the precipitous dry-up of milk secretion may be related either to necrosis caused by the inflammation or to induction of involution. The fact that all the treated goats kidded and their sequential milk production in both udder halves was similar to the previous lactation (data not shown) suggests that treatment imitated natural phenomena rather than inducing a necrotic response that would irreversibly damage the secretory function of the udder.
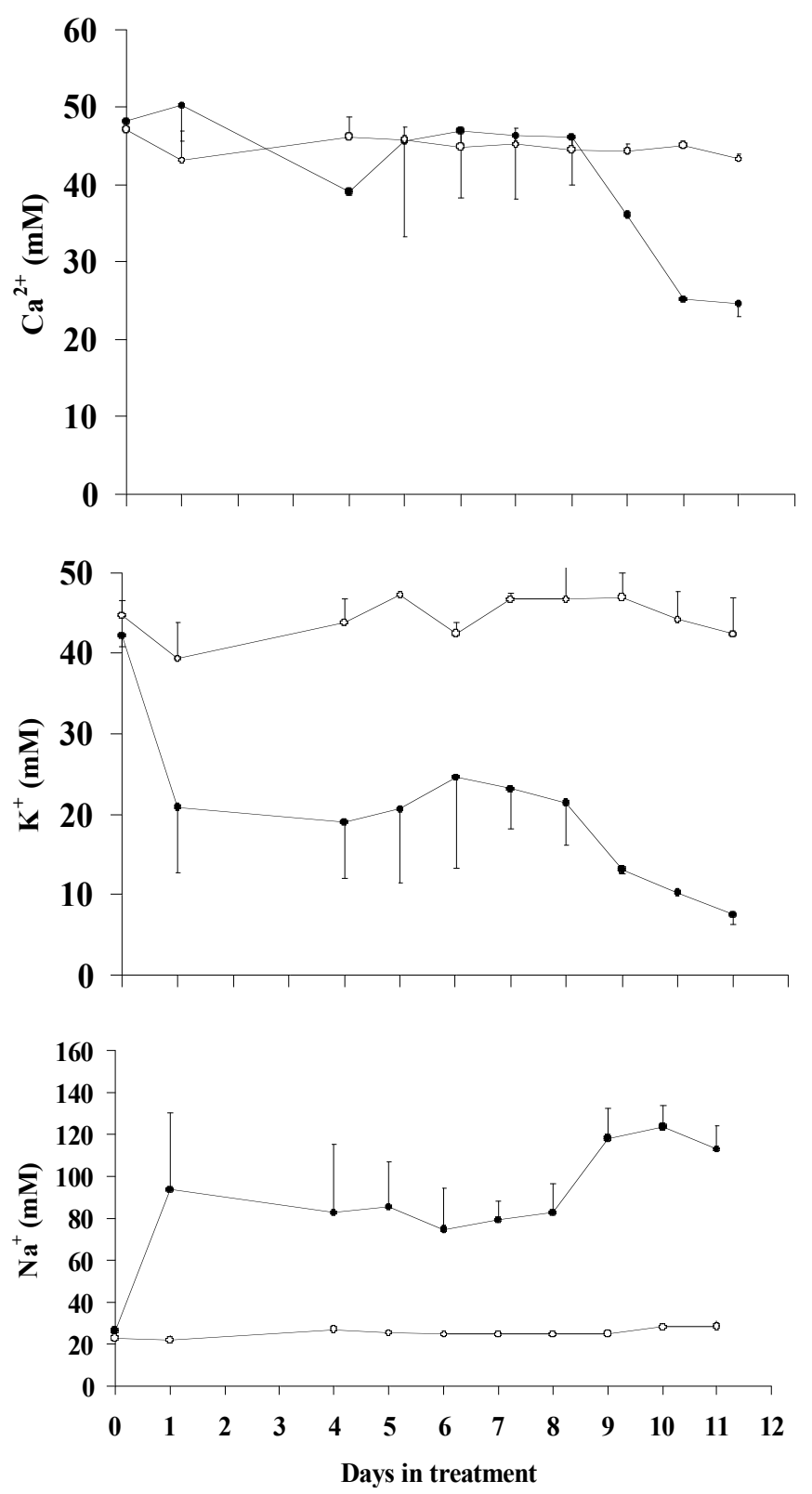

Fig. (3). Concentration of $\mathrm{Ca}^{2+}, \mathrm{K}^{+}$and $\mathrm{Na}^{+}$in milk of udder halves of goats subjected to intra-mammary injection of Saponins; Merck saponin (E. Merck No. 7695; full circles) or control solutions (open circles). Means are different from day 9 in treatment for $\mathrm{Ca}^{2+}$ and from day 1 for $\mathrm{K}^{+}$and $\mathrm{Na}^{+}(P<0.05)$.

\section{ABBREVIATIONS}

$\begin{array}{lll}\mathrm{TJ} & = & \text { Tight junction } \\ \mathrm{CN} & = & \text { Casein }\end{array}$

\section{REFERENCES}

[1] Quarrie LH, Addey CV, Wilde CJ. Local regulation of mammary apoptosis in the lactating goat. Biochem Soc Trans 1994; 22(2): $178 \mathrm{~S}$.

[2] Quarrie LH, Addey CV, Wilde CJ. Programmed cell death during mammary tissue involution induced by weaning, litter removal, and milk stasis. J Cell Physiol 1996; 168(3): 559-69.

[3] Glauert AM, Dingle JT, Lucy JA. Action of saponin on biological membranes. Nature 1962; 196: 953-5. 
[4] Capuco AV, Akers RM. Mammary involution in dairy animals. J Mammary Gland Biol Neoplasia 1999; 4(2): 137-44.

[5] Wilde CJ, Knight CH, Flint DJ. Control of milk secretion and apoptosis during mammary involution. J Mammary Gland Biol Neoplasia 1999; 4(2): 129-36.

[6] Nguyen DA, Neville MC. Tight junction regulation in the mammary gland. J Mammary Gland Biol Neoplasia 1998; 3(3): 233-46.

[7] Corinne DA, Gavin JA, Aumelas A, Bonnet PA, Christian R. Isolation and structure elucidation of a highly haemolytic saponin from the Merck saponin extract using high-field gradient-enhanced NMR techniques. Carbohydr Res 1997; 302(1-2): 67-78.

[8] Politis I. Plasminogen activator system: implications for mammary cell growth and involution. J Dairy Sci 1996; 79(6): 1097-107.

[9] Neville MC, Peaker M. Ionized calcium in milk and the integrity of the mammary epithelium in the goat. J Physiol 1981; 313: 561-70.

[10] Pitelka DR, Taggart BN, Hamamoto ST. Effects of extracellular calcium depletion on membrane topography and occluding junctions of mammary epithelial cells in culture. J Cell Biol 1983; 96(3): 613-24.

[11] Stelwagen K, Farr VC, Davis SR, Prosser CG. EGTA-induced disruption of epithelial cell tight junctions in the lactating caprine mammary gland. Am J Physiol 1995; 269(4 Pt 2): R848-55.

[12] Shamay A, Shapiro F, Mabjeesh SJ, Silanikove N. Casein-derived phosphopeptides disrupt tight junction integrity, and precipitously dry up milk secretion in goats. Life Sci 2002; 70(23): 2707-19.

[13] Silanikove N, Shamay A, Shinder D, Moran A. Stress down regulates milk yield in cows by plasmin induced beta-casein product that blocks $\mathrm{K}+$ channels on the apical membranes. Life Sci 2000; 67(18): 2201-12.

[14] Kai L, Wang ZF, Xiao JS. L-type calcium channel blockade mechanisms of panaxadiol saponins against anoxic damage of cerebral cortical neurons isolated from rats. Zhongguo Yao Li Xue Bao 1998; 19(5): 455-8.

[15] Bei L, Hu T, Qian ZM, Shen X. Extracellular Ca2+ regulates the respiratory burst of human neutrophils. Biochim Biophys Acta 1998; 1404(3): 475-83.
[16] Yamasaki Y, Ito K, Enomoto Y, Sutko JL. Alterations by saponins of passive $\mathrm{Ca} 2+$ permeability and $\mathrm{Na}+-\mathrm{Ca} 2+$ exchange activity of canine cardiac sarcolemmal vesicles. Biochim Biophys Acta 1987; 897(3): 481-7.

[17] Gogelein H, Huby A. Interaction of saponin and digitonin with black lipid membranes and lipid monolayers. Biochim Biophys Acta $1984 ; 773(1): 32-8$.

[18] McManus OB, Harris GH, Giangiacomo KM, et al. An activator of calcium-dependent potassium channels isolated from a medicinal herb. Biochemistry 1993; 32(24): 6128-33.

[19] Authi KS, Rao GH, Evenden BJ, Crawford N. Action of guanosine 5'-[beta-thio]diphosphate on thrombin-induced activation and $\mathrm{Ca} 2+$ mobilization in saponin-permeabilized and intact human platelets. Biochem J 1988; 255(3): 885-93.

[20] Francis G, Kerem Z, Harinder PSM, Becker K. The biological action of saponins in animal systems: a review. The effects of saikosaponins on biological membranes. 2. Changes in electron spin resonance spectra from spin-labelled erythrocyte and erythrocyte ghost membranes. Br J Nutr 2002; 88(3): 587-605.

[21] Seeman P. Ultrastructure of membrane lesions in immune lysis, osmotic lysis and drug-induced lysis. Fed Proc 1974; 33(10): 211624.

[22] Brain K, Hadgraft J, Al-Shatalebi M. Membrane modifi-cation in activity of plant molluscicides. Planta Med 1990; 56: 663.

[23] Takechi M, Tanaka Y. Haemolytic time course differences between steroid and triterpenoid saponins. Planta Med 1995; 61(1): 76-7.

[24] SAS. SAS ${ }^{\circledR}$ User's Guide. Statistics, Version 5th Ed. 1985. SAS Inst. Inc., Cary, NC. SAS Inst. Inc., Cary, NC.

[25] Vallorosi CJ, Day KC, Zhao X, et al. Truncation of the betacatenin binding domain of E-cadherin precedes epithelial apoptosis during prostate and mammary involution. J Biol Chem 2000; 275(5): 3328-34

[26] Stelwagen K, Davis SR, Farr VC, Prosser CG, Sherlock RA. Mammary epithelial cell tight junction integrity and mammary blood flow during an extended milking interval in goats. J Dairy Sci 1994; 77(2): 426-32. 